\title{
DESBUROCRATIZAÇÃO: IMPACTOS NA INFORMATIZAÇÃO E CELERIDADE DO SERVIÇO PÚBLICO
}

\author{
Carlos César Sousa Cintra* \\ Ivone Rosana Fedel ${ }^{* *}$
}

\section{RESUMO}

Este artigo estuda os impactos da desburocratização no serviço público. Faz-se uma contextualização histórica da Administração Pública. Em seguida, relacionam-se os conceitos de burocracia e eficiência e apresentam-se quais os impactos do Programa Brasil Eficiente. Por último, avaliam-se os desafios frente a Lei da Desburocratização. Metodologicamente, adotou-se pesquisa bibliográfica e documental, complementada com a técnica de observação direta. Conclui-se que ainda há muitos obstáculos que dificultam o acesso fácil e simples pelos usuários. Dessa forma, faz-se necessária a atuação dos órgãos de controle para estabelecer metas e acompanhar os resultados da administração com vistas à desburocratização.

Palavras-chave: Desburocratização; Eficiência; Administração Pública; Controle Social; Resultado.

\section{DEBUREAUCRATIZATION: IMPACTS ON COMPUTERIZATION AND SPEED OF PUBLIC SERVICE}

\begin{abstract}
This paper studies the impacts of debureaucracy on public service. A historical contextualization of Public Administration is made. Then, the concepts of bureaucracy and efficiency are listed and the impacts of the program Programa Brasil Eficiente are presented. Finally, the challenges are assessing facing the Lei da Desburocratização. Methodologically, a bibliographic and documentary research was adopted, complemented with the technique of direct observation. It is concluded that there are still many obstacles that make it difficult for users to easily and easily access. Thus, the action of the control to set goals and monitor the results of administration with debureacratization.
\end{abstract}

Keywords: Debureaucratization; Efficiency; Public Administration; Social Control; Result.

\section{INTRODUÇÃO}

Algumas ações de desburocratização podem ser constatadas, é pouco, frente a necessidade de transformação digital do serviço público para dar mais celeridade e

\footnotetext{
* Doutor e Mestre pela Pontifícia Universidade Católica de São Paulo. Professor Adjunto da UFC-CE. Professor da Graduação e Pós-graduação da Unichristus. Professor Conferencista do IBET - Instituto Brasileiro de Direito Tributário. Membro do ICET - Instituto Cearense de Estudos Tributários. Advogado em Fortaleza.

*** Mestranda em Direito pela Unichristus. Especialista em Legislação, Perícia e Auditoria Ambiental e em Contabilidade Tributária. Graduada em Direito, Engenharia Civil e Ciências Contábeis. Auditora de Controle Externo no TCE-CE.
} 
economicidade à gestão pública. É imprescindível a atuação dos órgãos de controle interno e externo estabelecendo metas e acompanhando resultados obtidos.

$\mathrm{O}$ escritor Lima Barreto (s/d), que publicou a obra $O$ triste fim de Policarpo Quaresma, denuncia nessa narrativa os males da sociedade brasileira da época, dentre elas a burocracia das repartições públicas. Descreve o patriotismo do personagem principal que tem uma visão maravilhosa sobre o Brasil. $\mathrm{O}$ autor retrata um perfil irônico e sarcástico do funcionário público do Brasil. O romancista descreve o ambiente burocrático das repartições públicas brasileira, papelada amontoada, conversas e gozações. Na visão do autor, em regra, o ambiente era formado por pessoas sem consistência moral ou profissional para exercer o trabalho.

O governo de Trump realizou, nos Estado Unidos, ações para reduzir as regulamentações federais, que incluíram, dentre outras, a remoção de regras que dificultavam a expansão dos negócios e o descarte de papeladas burocráticas.O corte nos regulamentos excessivos resultou em uma economia da ordem de US\$ 570 milhões por ano nas agências federais daquele país.

No Brasil, o histórico burocrático culminou, no decorrer do tempo, por prejudicar a prestação de serviços públicos. Apesar do sociólogo Max Weber (1946) ter descrito, no início do século XX, o termo "burocracia" como uma estrutura baseada na racionalidade, a expressão adquiriu uma conotação negativa, relacionada principalmente ao que ele denominou de "disfunções" da burocracia, relacionados a exageros que provocam ineficiência do sistema. Contudo, a concepção original do autor, a burocracia é a única forma de lidar com a especialização das tarefas e sua maior complexidade, tornando necessária a implantação de um sistema de controle eficiente.

Eficiência, por sua vez, relaciona-se à otimização dos recursos da organização, de forma a alcançar o melhor produto. O Estado eficiente é aquele que garante o bom atendimento das necessidades com os menores custos para a sociedade. O modelo Weberiano de gestão burocrática tem como base a eficiência, a otimização, a celeridade e a economia.

O projeto de desburocratização no Brasil se iniciou com a publicação do Decreto $\mathrm{n}^{\circ}$ 9.094, de 17 de julho de 2017, dispondo sobre a simplificação do atendimento prestado aos usuários de serviços públicos. Esse normativo de desburocratização tem por objetivo, facilitar o acesso ao serviço público, economizar tempo e dinheiro e visa como resultado propiciar maior transparência na prestação dos serviços públicos. 
Dando andamento nesse projeto, foi sancionada a Lei $\mathrm{n}^{\mathbf{0}} 13.726$, de 08 de outubro de 2018, com objetivo de racionalizar atos e procedimentos administrativos da União, dos Estados, do Distrito Federal e dos Municípios. Citada lei é mais uma evolução no processo de desburocratização, com regras de simplificação e facilitação do acesso aos serviços públicos. Contudo, a promulgação de regramentos, por si só, não garante alcançar os objetivos propostos. Afigura-se necessário que ocorram alterações estruturais nos órgãos e entidades públicas para que se adequem ao conceito moderno de eficiência na gestão dos serviços públicos frente a evolução tecnológica.

Nesta perspectiva, este artigo objetiva precipuamente fazer uma crítica avaliativa do processo de desburocratização da administração pública brasileira, refletindo acerca dos impactos necessários nas estruturas física e tecnológica das entidades públicas para que se adaptem ao novo conceito de gestão eficiente, bem como avaliar quais os impactos dessas mudanças na celeridade do serviço público. Para atender o objetivo delimitado, adotou-se uma abordagem metodológica assentada em pesquisa bibliográfica e documental.

\section{EVOLUÇÃO HISTÓRICA DA ADMINISTRAÇÃO PÚBLICA NO BRASIL}

Desde os primórdios, ao Estado cabe a responsabilidade pela prestação dos serviços requerido pelo cidadão, tais como educação, saúde, segurança, habitação, saneamento, esporte, lazer e assistência social. O modelo de gestão pública para consecução dessa função vem se aperfeiçoando, mas ainda há muito para avançar.

Historicamente, a Administração Pública brasileira passou por três modelos diferentes de gestão, quais sejam: patrimonialista, burocrática e gerencial. A passagem de um modelo para o outro decorreu da evolução do Estado moderno, no qual se observa nitidamente mudanças na relação da sociedade com o patrimônio público.

Com o surgimento do Estado Liberal, teve origem a administração burocrática, que se propôs a romper com o modelo anterior, patrimonialista. A burocracia, que tem sua base no modelo racional-legal, buscou eliminar a subjetividade, o patrimonialismo e a ausência de controles do poder estatal. Segundo Abrucio e Loureiro (2018), o conceito de burocracia manifesta-se, via de regra, o imprescindível processo de racionalização e profissionalização das organizações no mundo atual, em virtude na necessidade de obter melhor desempenho na consecução de seus fins, diante da maior competição existente entre as organizações. 
A teoria da burocracia vem da premissa de que a burocracia é a organização eficiente por excelência. Assim, para conseguir eficiência, se explica nos mínimos detalhes como todos os procedimentos devem ser realizados. Para entender esse conceito, faz-se necessário compreender as principais características da burocracia definidas pelo próprio Weber (1946). Segundo o autor, a burocracia é dotada de aspectos legais fixos, regidas por leis ou normas administrativas (I), existe hierarquia organizada monocraticamente (II), o quadro de servidores se reveste de ocupantes de cargos imbuídos de know-how para realização de tarefas pré-determinadas e que atendam a procedimentos padrões (III), o treinamento especializado é um pressuposto (IV), a ocupação do cargo está vinculada à plena capacidade de trabalho do funcionário (V), o desempenho no cargo obedece a regras gerais (VI), a relação entre as pessoas deve se dar entre cargos (VII), a meritocracia deve ser respeitada (VIII), e os atos devem ser passíveis de registro, de forma a haver formalidade nas comunicações (IX).

Além disso, o autor menciona que precisão, velocidade, clareza, conhecimento dos arquivos, discrição, dentre outros atributos, são características intrínsecas da burocracia (WEBER, 1946). Já, Cordeiro (2017) entende que dessa forma, o modelo burocrático funciona perfeitamente se as condições necessárias estão presentes e forem aplicadas no gerenciamento da coisa pública e afirma que "a burocracia se mostra como um instrumento vigoroso capaz de garantir alta eficiência administrativa e prestar contribuições às intermitentes formas de gerenciamento".

Segundo Merton (1970, apud QUEIROZ, 2014) o mal funcionamento da gestão relacionado ao excesso de formalismo, de documentação e de papelório existe em virtude da disfunção da burocracia em decorrência de:

1) internalização das regras e apego aos regulamentos; 2) excesso de formalismo e de papelório; 3) resistência a mudanças; 4) despersonalização do relacionamento; 5) categorização como base do processo decisorial; 6) superconformidade às rotinas e aos procedimentos; 7) exibição de sinais de autoridade; e 8) dificuldade no atendimento a clientes e conflitos com o público (MERTON, 1970, apud QUEIROZ, 2014).

Na visão de Queiroz (2014) a burocracia tem por objetivo a máxima eficiência da organização, sendo necessário decidir por meios eficientes para efetivação das metas desejadas, bem como aplicar o conhecimento científico para elaborar as regras que irão direcionar a conduta em direção da eficiência. Assim, se utilizada de maneira adequada a burocracia torna-se aliada do administrador que pode escolher a metodologia mais apropriada para consecução de seu objetivo. 
Contudo, a evolução do modelo de administração pública não foi absorvida no Brasil, que mantém práticas típicas do patrimonialismo como as negociações políticopartidárias de cargos comissionados, bem como a praxe do nepotismo (PEREZ, 2016).

É certo que a influência da burocracia weberiana na administração pública é indispensável para a sociedade atual e necessária para a ordem democrática. Diferente do conceito desvirtuado que hoje se tem do termo, onde a denominação burocracia se associa aos defeitos do sistema que emperram a máquina administrativa, a expressão burocracia tem origem no propósito de alcançar a eficiência e a eficácia na gestão pública, motivo pelo qual sua essência não deve ser afastada da gestão pública.

De seu turno, no Governo Fernando Henrique Cardoso surgiu modelo de gestão gerencial, com a elaboração do Plano Diretor da Reforma do Aparelho do Estado, cujo modelo pautou-se no seguinte: descentralização política e administrativa; mudança do modelo piramidal para estruturas com poucos níveis hierárquicos; confiança limitada ao invés da desconfiança total; controle a posteriori dos processos administrativos; e administração voltada ao atendimento do cidadão (VIOLIN, 2007).

A administração pública gerencial partiu da premissa que se chegou a um nível cultural e político em que o patrimonialismo está relegado e que a democracia já se tornou um regime político consolidado (PEREIRA, 1997). Violin (2007) assevera que esse modelo de gestão tem por base a necessidade de redução de custos, a melhoria na qualidade e eficiência dos serviços, tendo o cidadão como beneficiário. Contudo, segundo o autor, mantêm-se alguns princípios da burocracia, tais como a admissão por concurso público, sistema estruturado e universal de remunerações, carreiras, avaliações de desempenho, treinamento sistemático.

Nessa perspectiva, sobressai o modelo gerencial, em função dos novos desafios que exigem uma administração mais competitiva, que prioriza a proteção dos direitos individuais em detrimento à participação política, que atribui maior valor ao mercado do que a esfera pública e submerge o conceito de cidadania, pautado na competição entre as organizações com chave para garantir a qualidade dos serviços públicos que indiquem melhores resultados.

Entretanto, verifica-se que o modelo gerencial não atende mais a demanda dos conceitos atuais de gestão. Com os avanços tecnológicos, há necessidade de alterações tanto na estrutura física da administração pública, como na metodologia de prestação do serviço público. Não se concebe mais que o cidadão passe horas esperando o receber um documento 
que já existe na forma virtual. É inaceitável, que o cidadão necessite comparecer fisicamente ao serviço de saúde para marcar uma consulta, se existem aplicativos que podem realizar tal procedimento por meio de alguns cliques no aparelho de celular. Enfim, há que se moldar a gestão pública aos novos modelos de tecnologia para que a prestação de serviço público seja realizada de forma eficiente e transparente.

\section{A EFICIÊNCIA NA DESBUROCRATIZAÇÃO DA GESTÃo PÚBLICA}

Com o advento da Emenda Constitucional de n ${ }^{\circ}$ 19, de 04 de julho de 1998, ocorreu uma das grandes reformas administrativas no país, com a adoção de medidas do modelo de administração gerencial, estabelecendo a eficiência como um dos fundamentos dessa reforma, como se pode verificar na exposição de motivos Ministerial n ${ }^{\circ}$ 49, de 18 de agosto de 1995, in verbis (BRASIL, 1995):

No difícil contexto do retorno a democracia, que em nosso país foi simultâneo a crise financeira do Estado, a Constituição de 1988 corporificou uma concepção de administração pública verticalizada, hierárquica, rígida, que favoreceu a proliferação de controles muitas vezes desnecessários. Cumpre agora, reavaliar algumas das opções e modelos adotados, assimilando novos conceitos que reorientem a ação estatal em direção a eficiência e à qualidade dos serviços prestados ao cidadão.

Essa Emenda Constitucional foi o marco da mudança no modelo de administração do Estado brasileiro, que objetivou incrementar a qualidade do serviço público colocado à disposição do cidadão (CARVALHO, 2016). A partir de então, o termo eficiência passou a fazer parte do rol de princípios estabelecidos no caput do art. 37 da Carta Magna.

A alteração constitucional teve por objetivo ressaltar a eficiência, mediante a adoção de mecanismos que visaram a excelência administrativa e o foco no cidadão. Garantir uma gestão mais eficiente com vistas a proporcionar mais qualidade na prestação do serviço público ainda é um dos propósitos da administração pública, visto que o avanço da tecnologia modificou a forma de acessos aos serviços disponíveis no mercado.

Contudo, faz-se necessário estabelecer a distinção entre os termos eficiência, eficácia e efetividade. A eficiência está relacionada com o método de realizar a atividade, propugnando a forma de realizar a maior quantidade de coisa com o menor dispêndio de recursos possível, enquanto a eficácia diz respeito aos instrumentos utilizados pelo servidor público para executar tais atividades. Já, a efetividade afere os resultados obtidos mensurando 
em que medida as ações administrativas trouxeram benefícios para a população (QUEIROZ, 2014). Assim, para se ter um estado eficiente é necessário controlar os resultados.

Perez (2016, p. 84) assevera que o que se deseja é "uma Administração Pública que alcance a excelência nas suas funções, com eficiência, eficácia e efetividade, pois o resultado final é relevante para o cidadão". Nos dias atuais, não basta estar preocupado com os desperdícios ativos de recursos. É necessário prevenir desperdícios antes que eles ocorram. Mesmo atividades como de auditorias para apuração de irregularidades e atos fraudulentos, devem ser justificadas indicando a economia gerada decorrente da contenção do dano e indicando os ganhos de eficiência para a Administração Pública (OLIVEIRA, 2017).

Nos dizeres de Chicóski (2004), com o advento do Estado de Bem-estar Social a eficiência se tornou um dos objetivos da gestão e passou a ser vinculada ao modelo gerencial de administração pública em oposição ao modelo racional-burocrático, que tem legitimidade no procedimento e prima pelo resultado. Loureiro (1995, p. 123-3, apud CHICÓSKI, 2004, p. 97) apresenta um superconceito de eficiência com base na sua pluridimensionalidade em que se extrai quatro dimensões, quais sejam: eficácia, otimização, celeridade e economia.

Desta feita, examinando os conceitos da burocracia e da eficiência, percebe-se que o modelo burocrático de gestão é o instrumento para se atingir a eficiência na medida que os fundamentos básicos da gestão burocrática visam atingir a gestão eficiente. Contudo Chicóski (2004, p. 25) aponta que "o verdadeiro problema a ser enfrentado para a manutenção da legitimidade estatal, ou mesmo para se chegar a essa legitimidade, é adequar a eficiência dos meios administrativos aos fins de um Estado Social e Democrático de Direito”.

Percebe-se que o aperfeiçoamento do aparelho estatal no Brasil é necessário visto que o modelo burocrático como é atualmente adotado na prestação dos serviços públicos não atende mais as crescentes demandas do usuário do serviço público. A sociedade dispõe de um maior número de informações e os recursos estão cada vez mais escassos. Exige-se, portanto, uma mudança do mecanismo de atuação da gestão no sentido de se adequar às tecnologias emergentes.

É nessa senda que deve haver o direcionamento de estudos em prol de melhores práticas na administração, o estabelecimento de padrões de procedimento, a agregação de métodos de controle e a propagação de novas técnicas para a realização das atividades são balizadoras da produtividade organizacional. A implementação de novas tecnologias permite a majoração da eficiência, com otimização dos gastos com vistas a obter melhores resultados. 
As tecnologias disponíveis na atualidade permitem o controle social mais efetivo, permitindo a participação cidadã nas diversas fases do ciclo de gestão (OLIVEIRA, 2017).

Nesse sentido, como forma de atingir esse objetivo de adequação aos atuais padrões da coletividade, o governo federal instituiu o programa "Brasil Eficiente" que tem como uma das medidas integrar, em uma única plataforma, diversos serviços do governo, com objetivo de facilitar a vida do cidadão e promover a economia. Como aduz Silva (2017, Online):

\begin{abstract}
Muitas vezes as etapas burocráticas de um serviço ferem diretamente o princípio constitucional da eficiência na administração pública por não aplicar economia de recursos, celeridade no serviço e qualidade no serviço. A desburocratização destinase, portanto, a atuar nas disfunções da burocracia, eliminando-as ou reduzindo-as drasticamente para aumentar o grau de eficiência e efetividade da administração pública.
\end{abstract}

Assim, a eficiência administrativa, como a melhor realização possível da gestão dos interesses públicos, precisa ser posta em termos de plena satisfação dos administrados com os menores custos para a sociedade.

\title{
4 A DESBUROCRATIZAÇÃO DO PROGRAMA BASIL EFICIENTE E OS IMPACTOS NA PRESTAÇÃO DO SERVIÇO PÚBLICO
}

Em 07 de março de 2017, foi criado o Conselho Nacional para Desburocratização (Programa Brasil Eficiente), com o objetivo de formular políticas públicas para simplificar a administração pública e melhorar os serviços para o cidadão (BRASIL, 2017).

Dentre as medidas que o programa prioriza estão: a digitalização de serviços públicos, a celeridade na emissão de documentos, a marcação de consultas no sistema único de saúde, o prontuário médico eletrônico e interligado entre todos os entes públicos e a integração de banco de dados (BRASIL, 2017).

O Programa Brasil Eficiente reúne medidas para desburocratizar, simplificar, modernizar e melhorar a prestação de serviços para a sociedade. A revolução proposta nesse programa visa integrar os bancos de dados da administração pública, permitindo uma economia de recursos financeiros. Segundo estudos realizados no Canadá, no Reino Unido, na Noruega e na Austrália, um atendimento presencial nos serviços públicos custa, em média, US\$ 14. "Quando o mesmo serviço é prestado de forma on-line, o custo baixa para US\$ 0,39, o que representa uma economia de 97\% aos cofres públicos” (BRASIL, 2017).

Merece destaque, ainda, o Decreto ${ }^{\circ}$ 9.203, de 22 de novembro de 2017, que dispõe sobre "a política de governança da administração pública e estipula, dentre as diretrizes da 
governança pública, a promoção da simplificação administrativa, a modernização da gestão pública e a integração dos serviços, especialmente aqueles prestados por meio eletrônico”.

Recentemente, foi publicada a Lei $\mathrm{n}^{\circ}$ 13.726, de 8 de outubro de 2018 (Lei da Desburocratização), que objetiva racionalizar os atos e procedimentos administrativos dos Poderes da União, dos Estados, do Distrito Federal e dos Municípios mediante a supressão ou a simplificação de formalidades ou exigências desnecessárias, cujo custo econômico ou social, tanto para o erário como para o cidadão, seja superior ao eventual risco de fraude.

Os dispositivos dessa lei não são a grande novidade no âmbito das medidas de desburocratização que foram adotadas em nível nacional, nos últimos anos. Seguem, a bem da verdade, o caminho que já se via gradativamente sendo incorporado ao ordenamento jurídico brasileiro.

Os instrumentos normativos visam dar mais eficiência ao serviço público, dever consagrado desde o Decreto-Lei ${ }^{\circ}$ 200, de 25 de fevereiro de 1967, como dever de boa administração pública. Ora, se tal obrigação existe desde a citada data, então qual motivo de se estabelecer novas regras para consecução do mesmo objetivo? A resposta está na necessidade de adequar a prestação do serviço público ao desenvolvimento da tecnologia e, com essa ferramenta, ser mais eficiente na gestão pública. Não é mais admissível que, por exemplo, a aferição da autenticidade de assinaturas e documentos seja realizado de forma manual se hoje existem mecanismos tecnológicos bem mais céleres e confiáveis.

É imprescindível ajustar a atividade administrativa a esse novo padrão de atendimento ao interesse público. Gomes (2017), ao pronunciar seu voto ao Projeto de Lei $\mathrm{n}^{\circ}$ 7.064, de 2017, assevera que “A burocratização excessiva e desnecessária não apenas torna ineficiente os atos e procedimentos administrativos como também priva o cidadão do efetivo exercício de seus bens e direitos juridicamente tutelados".

De lá para cá as mudanças ocorridas na gestão da coisa pública já fazem diferença nos resultados obtidos no desempenho dos serviços públicos, os quais podem ser aferidos pelo cidadão por meio do Painel de Monitoramento de Serviços Federais. "A ferramenta de monitoramento é um dos componentes previstos na Plataforma de Cidadania Digital, instituída por meio do Decreto n 8.936, de 19 de dezembro de 2016” (BRASIL, 2016).

Segundo notícia veiculada no portal eletrônico da Casa Civil, entre junho de 2017 e fevereiro de 2018, “o Governo Federal concluiu 78 medidas de modernização da gestão, simplificação administrativa e melhoria na prestação de serviços públicos. As iniciativas de 
desburocratização integram 226 propostas feitas pelos ministérios, no âmbito do programa Brasil Eficiente" (PADILHA, 2018).

Nesse âmbito, foi criado o Portal de Serviços do Governo Federal que tem por objetivo aproximar os serviços públicos do usuário. A página eletrônica (http://painelservicos.servicos.gov.br/) reúne todos os serviços e permite aos cidadãos, empresas e gestores públicos acessar informações e efetuar transações de serviços digitais com mais eficácia. Já são mais de 2,8 mil serviços públicos disponíveis, dos quais mais de $42 \%$ totalmente digitais. Está em andamento, pelo Governo Federal, a unificação dos cadastros dos cidadãos para que, com apenas uma conta, seja possível acessar qualquer dos serviços públicos federais.

"No portal, é possível o cidadão encontrar informações sobre taxas, documentos necessários, forma de prestação do serviço (presencial ou digital), bem como endereços e outras formas de contato com os órgãos responsáveis pela prestação do serviço" (BRASIL, 2017). As empresas também têm à disposição informações sobre o que é necessário para regularizar a situação cadastral junto à Receita Federal, por exemplo, além de emissão de certidões, orientações em geral para abertura de negócio, elaboração de termo de rescisão, entre outros.

Segundo o Secretário de Gestão do Ministério do Planejamento e Gestão, Gleisson Rubin (2018), o portal é uma ferramenta de transparência e controle social, além de ser uma “importante fonte de informações para tomada de decisão, para que os gestores possam promover a simplificação e a melhoria contínua dos processos e do atendimento ao cidadão, com saltos de qualidade".

A medida adotada pelo governo brasileiro de disponibilizar os serviços públicos digitais foi o principal componente a contribuir para elevar a colocação do Brasil da $51^{\mathrm{a}}$, que ocupava em 2016, para $44^{a}$ posição, em 2018, conforme revela o Relatório de Governo Eletrônico das Nações Unidas (ONU, 2018). A pesquisa, que avalia o status de desenvolvimento do governo eletrônico dos 193 (cento e noventa e três) países-membros da ONU, indica que a oferta de serviços públicos digitais no Brasil passou de 0,73, em 2016, para 0,92, em 2018. No índice geral de desenvolvimento de governo eletrônico, o Brasil ficou atrás apenas do Chile, Argentina e Uruguai.

O grande destaque do Brasil no relatório da ONU é "no ranking de participação social por meios digitais. O país agora é o líder na América Latina, na $12^{\text {a }}$ colocação, com um 
índice de participação social por meios digitais (E-participation Index) de 0,97. Na última pesquisa, o País ocupava o $37^{\circ}$ lugar, com um índice de 0,72” (ONU, 2018).

Conclui-se, portanto, que as medidas adotadas pelo governo federal estão avançando na direção das novas tecnológicas e contribuirá para a prestação de um serviço público mais eficiente, célere, econômico, aproximando, assim, o serviço público dos seus usuários.

\section{OS DESAFIOS NOS SERVIÇOS PÚBLICOS FRENTE À LEI DA DESBUROCRATIZAÇÃO}

Diante da evolução tecnológica, desburocratizar é um movimento que não se encerra, motivo pelo qual é necessário sempre buscar meios de facilitar o acesso da população ao governo. Impende otimizar a atividade administrativa nas diversas esferas, ao passo que não se tolera mais o aumento das despesas, especialmente com a crise econômica que assola o país. Cumpre repensar sobre como racionalizar e dar mais eficiência à gestão.

A publicação da Lei da Desburocratização vai ao encontro dos avanços tecnológicos disponíveis quando dispensa o reconhecimento de firma e a autenticação de documentos na relação entre o cidadão e o poder público. O objetivo dessa lei é simplificar os procedimentos administrativos da União, dos Estados, do Distrito Federal e dos Municípios, acabando com uma série de formalidades ou exigências consideradas desnecessárias ou superpostas.

A criação do "Selo de Desburocratização e Simplificação", instituído no art. $7^{\circ}$, da Lei $\mathrm{n}^{\circ}$ 13.726, de 8 de outubro de 2018, “tem por finalidade reconhecer a eficiência da administração pública, bem como estimular projetos, programas e práticas que simplifiquem e melhorem o atendimento aos usuários dos serviços públicos”.

Resultados da pesquisa realizada pela Federação das Indústrias do Estado de São Paulo (FIESP, 2017) apontam que $84 \%$ da população brasileira acredita que o país é burocrático e que seu excesso é prejudicial e dificulta o desenvolvimento do Brasil. Nesse sentido, a regulamentação de ferramentas digitais pela Lei da Desburocratização poderá proporcionar mais celeridade e menos burocracia para as atividades realizadas pela administração pública.

Com os avanços da tecnologia e da conectividade entre as ferramentas, as pessoas resolvem problemas de forma célere com os diversos recursos disponíveis no smartphone, computadores e até em relógios digitais. É tempo de as empresas públicas entrarem na era 
digital e disponibilizarem soluções rápidas e eficientes. Contudo, é necessário que os órgãos e entidades públicas se adéquem para permitir que as ferramentas sejam criadas.

Os desafios são muitos. A Lei da Desburocratização vem ser mais um amparo legal para que os entes públicos adotem medidas para avançar buscando novas tecnologias. A criação de leis e regras não é suficiente para garantir a efetiva modificação da gestão do serviço público. É necessário a reestruturação física e tecnológica nas estruturas da administração pública para se adequar ao novo conceito de eficiência na gestão dos serviços públicos, caso contrário, as regras serão apenas letra morta no papel.

Em 2015, o Tribunal de Contas da União realizou uma ampla ação de controle para avaliar as políticas públicas do governo federal relacionadas à inclusão digital. Os resultados constam no Acórdão TCU n ${ }^{\circ}$ 2.151/2015 - Plenário que aponta os principais desafios de inclusão digital e social enfrentados pelo cidadão excluído digitalmente: acesso efetivo do cidadão, impactado pelos custos e pela infraestrutura disponível; habilidade, afeta a sua capacidade de usar as tecnologias da informação e comunicação; motivação, relacionado ao estímulo do indivíduo em desejar utilizar as TIC's; e confiança, que se refere a aspectos da segurança da informação (BRASIL, 2015).

Assim, para superar esses obstáculos é necessário haver melhorias nas “disponibilidades de infraestrutura física de telecomunicação, bem como investimentos para inclusão dos indivíduos na sociedade, que depende de aplicação de recursos na educação, bem como ações efetivas que promovam mudanças culturais" (OLIVEIRA, 2017).

A Lei $n^{\circ} 13.726$, de 8 de outubro de 2018, estabeleceu diretrizes para reestruturação dos órgãos públicos com implementação de novas tecnologias e capacitação dos servidores. $\mathrm{O}$ art. $5^{\circ}$ da referida lei prevê a possibilidade de criação de grupos setoriais de trabalho para identificar dispositivos legais que façam exigências descabidas, exageradas, desnecessárias ou redundantes, sugerindo medidas que visem eliminar o excesso de burocracia.

$\mathrm{Na}$ esfera federal foram criadas duas novas entidades a Secretaria Especial de Modernização do Estado - SEME, que integra a estrutura da Secretaria-Geral da Presidência da República e a Secretaria Especial de Desburocratização - SGD, Gestão e Governo Digital, como parte integrante da estrutura do Ministério da Economia.

A SEME (2019) tem competência "para elaborar e executar o plano de reestruturação de processos, procedimentos, acesso à informação, controles e gestão de resultados viabilizando a melhoria da administração pública; e propor medidas, planos e projetos de 
ampliação do acesso e facilitação do atendimento das demandas do cidadão" (Decretos $\mathrm{n}^{\circ}$ 9.670, de 2 de janeiro de 2019). Já, à SGD compete supervisionar os projetos de eficiência administrativa e modernização governamental (Decreto $\mathrm{n}^{\circ}$ 9.745, de 08 de abril de 2019).

A SEME (2019) tem como atribuição, ainda, disponibilizar serviços mais ágeis, acessíveis, simples e eficientes aos cidadãos, de forma a assegurar que ações ou projetos de relevância do Governo Federal, sob a ótica da Modernização, sejam executados, transformando metas em resultados efetivamente concretos.

Segundo Brandão (2019), “uma das ações já articuladas é a criação de uma base digital envolvendo os ministérios da Justiça; da Economia; da Ciência, Tecnologia, Inovações e Comunicações; e da Secretaria-Geral da Presidência". Referida base visa unificar documentos como Registro Geral (RG), Cadastro de Pessoa Física (CPF), Carteira Nacional de Habilitação (CNH), Carteira de Trabalho, Título de Eleitor e Certificado de Reservista.

Outro importante avanço, na esfera federal, foi a instituição do portal único "gov.br", por meio do Decreto n ${ }^{\circ}$ 9.756, de 11 de abril de 2019, que centralizará em um único portal as informações e os serviços públicos prestados pelo Governo Federal. Segundo notícia veiculada no Ministério da Economia (BRASIL, 2019), existem hoje mais de 1500 sítios na internet que oferecem informações aos cidadãos de forma esparsa e ineficaz, impossibilitando um bom atendimento ao usuário. A SGD deverá disponibilizar a solução técnica "gov.br" para adesão aos órgãos das entidades da administração pública federal, enquanto à SEME deverá articular com os gestores públicos e monitorar a tarefa de consolidação do portal.

As mudanças não param por aí. Na esfera estadual, o Governo do Estado do Ceará tem como meta ter um governo $100 \%$ digital até 2023, de forma que todos os serviços públicos possam ser acessados diretamente de uma plataforma digital (CEARÁ, 2019). Para atingir a meta proposta, em março de 2019, o Estado promoveu capacitação, com foco nos serviços públicos que passarão a ser exclusivamente digital. O objetivo do treinamento foi ensinar a utilização das ferramentas digitais e ter familiaridade com os recursos tecnológicos.

No Rio Grande do Sul, foi criado "o Conselho Estadual de Desburocratização e Empreendedorismo, vinculado à Secretaria de Governança e Gestão Estratégica - SGGE, que, em parceria com o Serviço Brasileiro de Apoio às Micro e Pequenas Empresas - SEBRAE”, tem a missão de coordenar "a implementação da política de desburocratização no âmbito do Poder Executivo e de servir como mecanismo de proteção e participação dos usuários de serviços públicos” (BRASIL, 2017). 
No âmbito municipal, em agosto de 2017, a Prefeitura Municipal de Fortaleza lançou o Programa Fortaleza Competitiva que tem o foco na desburocratização e envolve ações para diminuir o tempo de abertura de empresas na cidade, além de facilitar a vida da população, modernizando serviços por meio de ferramentas online (FORTALEZA, 2017).

No primeiro ano de implantação do Programa Fortaleza Competitiva, o Fortaleza
Online alcançou o total de 30 serviços disponíveis para a população e agilizou os
trâmites do licenciamento, por meio da redução do tempo da compensação bancária
de $48 \mathrm{~h}$, para 30 minutos. A plataforma digital pode ser acessada a qualquer hora e
em qualquer lugar, permitindo que $90 \%$ dos licenciamentos do município de
Fortaleza sejam feitos de forma online (FORTALEZA, 2017).

Além disso, para facilitar ainda mais a vida do cidadão, a Prefeitura de Fortaleza publicou o Decreto $\mathrm{n}^{\mathrm{o}}$ 14.335, de 12 de dezembro de 2018, que estabelece regras para simplificar os procedimentos de licenciamentos, emissão de documentos, autorizações e permissões de natureza urbana e ambiental. A iniciativa faz parte do Programa Fortaleza Competitiva (FORTALEZA, 2019).

Com o objetivo de aproximar os serviços públicos do usuário e permitir o controle social, foi desenvolvida pelo Governo Federal uma ferramenta denominada Simplifique. Esse instrumento é obrigatório em toda a administração pública federal e permite ao cidadão fazer reclamações caso o órgão público descumpra a Lei da Desburocratização. Além de reclamações, é possível solicitar também mudanças que ampliem a qualidade e facilitem o acesso e a execução do serviço público. Caso uma autarquia solicite informações eleitorais, o cidadão não precisará apresentar os comprovantes, a própria entidade terá de buscar as informações nos bancos de dados da Justiça Eleitoral. Acaso a instituição se recuse a fazer, o cidadão pode efetuar uma reclamação no Simplifique, por meio de formulário disponível no endereço eletrônico http://www.simplifique.gov.br/.

Apesar de grandes esforços empreendidos para desburocratizar a máquina pública, os resultados ainda se mostram insignificantes, visto que a maior parte dos serviços ainda não é digital, conforme consta no Relatório de Levantamento da auditoria realizada, em 2018, pelo Tribunal de Contas da União (processo $\mathrm{n}^{\circ}$ 023.283/2018-1), com o objetivo identificar e avaliar ações de desburocratização de serviços públicos prestados ao cidadão. "Restou demonstrado que, em 2017, do total de 1.740 serviços, 546 estavam em estágio no qual todas as etapas eram digitais (cerca de 31\%)" (BRASIL, 2018).

Nesse sentido, o Tribunal decidiu acompanhar a execução das ações de governo voltadas à desburocratização e simplificação dos serviços por meio da transformação digital. 
Para realização dessa ação, o TCU realizará, durante seis anos, de 2019 a 2024, o acompanhamento dos procedimentos realizados por meio do mapeamento de cinco grandes eixos: Eixo 1 - ações de desburocratização dos serviços públicos, entre outras, a implantação da Plataforma de Cidadania Digital; Eixo 2 - Acompanhar as estratégias de desburocratização em áreas específicas, tais como saúde, educação, segurança; Eixo 3 - avaliar a efetividade das ações de desburocratização, verificando se os resultados levam à prestação de serviços públicos mais simples, rápidos e baratos, Eixo 4 - aferir se há continuidade dos esforços de desburocratização; e Eixo 5 - articulação dos entes dos demais poderes e demais esferas da Federação, com capacitação de tribunais de contas estaduais e municipais e acompanhamento dos esforços de desburocratização em outras esferas da federação. Nesse sentido foi a decisão do TCU por meio do Acórdão no 1103/2019 (TCU, 2019), in verbis:

\footnotetext{
Acórdão nº 1103/2019 - TCU - TC 023.283/2018-1

9.1. determinar a constituição de processo apartado para dar início à implementação das ações de controle constantes da estratégia de fiscalização definida no presente levantamento, que visem a induzir a desburocratização de serviços públicos voltados aos cidadãos no âmbito da Administração Pública Federal, e que devem contemplar, nesta primeira etapa, questões relacionadas: à implantação da Plataforma de Cidadania Digital; ao compartilhamento de dados entre órgãos e entidades federais; e à implantação da Identificação Civil Nacional;
}

Pelo exposto, são muitos os desafios nos serviços públicos frente à lei da desburocratização. Alguns avanços já podem ser constatados, mas ainda é pouco frente a necessidade de transformação digital do serviço público para dar mais celeridade e economicidade à gestão pública.

Mostra-se imprescindível a atuação dos órgãos de controle interno e externo estabelecendo metas e acompanhando resultados obtidos. Somente com o controle das ações será possível induzir a desburocratização dos serviços públicos e avaliar se os resultados obtidos com as novas tecnologias implementadas resultam em serviços públicos mais eficientes, acessíveis, transparentes e econômicos.

\section{CONSIDERAÇÕES FINAIS}

Diante do exposto, conclui-se que o modelo burocrático de gestão é o instrumento ideal para se atingir a excelência na administração pública, resultando em atividades eficientes, eficazes e econômicas, além de evitar falhas e fraudes na execução dos procedimentos. Contudo, os estudos apontaram que, no Brasil, ocorreu o desvirtuamento do 
modelo burocrático fundado nas premissas básicas estabelecidas por Weber. Além disso, a administração pública não tem acompanhado os avanços tecnológicos, o que demonstra a necessidade de aperfeiçoamento do aparelho estatal brasileiro, por meio da desburocratização, o que significa tratar as disfunções burocráticas.

O processo de desburocratização, no Brasil, não é recente, data de 1967, com a edição do Decreto-Lei n 200, de 25 de fevereiro de 1967. De lá para cá várias foram as ações implementadas mas, apesar dos esforços realizados, não ocorreram grandes avanços. Dessa forma, a Lei $\mathrm{n}^{\mathrm{o}} 13.279$, de 8 de outubro de 2018, denominada Lei da Desburocratização, é mais um passo no processo de desburocratização.

Contudo, para que ocorra a implementação das medidas estabelecidas pela referida lei é necessário a reestruturação física e tecnológica nas estruturas das entidades públicas, o que requer grandes investimentos. Além disso, é necessário capacitar tanto os agentes públicos como os usuários dos serviços públicos para que ocorra uma efetiva inclusão digital e social.

A instituição do portal único "gov.br" centralizando as informações institucionais, notícias e serviços públicos prestados pelo Governo Federal sinaliza um grande progresso na facilitação do acesso às informações que hoje são veiculados em mais de 1500 sítios na internet. Há avanços também nas esferas estaduais, como o projeto implementado pelo Estado do Ceará denominado governo 100\% digital; e municipais, como o Programa Fortaleza Competitiva, da Prefeitura Municipal de Fortaleza.

Apesar das recentes alterações na gestão pública rumo à desburocratização, os resultados se mostram insignificantes, visto o caminho a percorrer. Em auditoria realizada pelo TCU, restou constatado que os principais obstáculos para efetivação da desburocratização são: "lentidão da implementação das iniciativas de desburocratização com o uso da transformação digital, ausência de integração plena dos serviços públicos à Plataforma de Cidadania Digital e ausência de gestão de riscos para a implementação de controles internos relativos aos serviços públicos" (TCU, 2019). O resultado desse trabalho é um balizador para as ações que devem ser realizadas pelos entes estatais no sentido de desburocratizar a máquina pública e ofertar um serviço público eficiente.

Entende-se que a principal barreira para avançar no processo de desburocratização é falta de obrigatoriedade de transformação digital dos serviços públicos e a ausência de metas e de prazos para o cumprimento das ações definidas nos regramentos vigentes. É possível 
contornar essa falha e, para isso, acredita-se que uma das medidas já foi adotada pelo TCU, que determinou a realização de ações de controle durante o prazo de seis anos (2019 a 2024). Nesse período, o Tribunal irá acompanhar as estratégias de desburocratização em áreas específicas, avaliar a efetividade dessas ações, aferir se há continuidade do processo e realizar a articulação entre os entes da federação.

Acredita-se que a atuação dos órgãos de controle interno e externos é forma de avaliar as políticas públicas e exigir o cumprimento de metas. Afinal, de que adianta a edição de leis, decretos e regulamentos se não há a exigência do cumprimento das regras estabelecidas? A motivação para continuar o processo de desburocratização é comprovar que após esse processo a administração pública está ofertando ao cidadão um serviço público mais eficiente, eficaz e econômico para o cidadão.

\section{REFERÊNCIAS}

ABRUCIO, Fernando Luiz; LOUREIRO, Rita Maria. Burocracia e políticas públicas no Brasil: interseções analíticas / Organizadores: Roberto Pires, Gabriela Lotta, Vanessa Elias de Oliveira. Brasília: Ipea: Enap. 2018. p, 24. ISBN: 978-85-7811-331-5.

BARRETO, Lima. Triste fim de Policarpo Quaresma. Rio de Janeiro, Editora Record, s/d. Disponível em: http://www.ebooksbrasil.org/adobeebook/policarpoE.pdf. Acesso em: 06 jun. 2019.

BATISTA JÚNIOR, Onofre Alves. Princípio constitucional da eficiência administrativa. 2. ed. rev. e atual. Belo Horizonte: Fórum, 2012.

BRANDÃO, Marcelo. Governo federal cria secretaria para agilizar serviços ao cidadão. Brasília, 2019. Disponível em: http://agenciabrasil.ebc.com.br/politica/noticia/2019-

01/governo-federal-cria-secretaria-para-desburocratizar-vida-do-cidadao. Acesso em: 19 mai. 2019.

BRASIL. Câmara dos Deputados. Exposição de motivos interministerial no 49, de 18 de agosto de 1995. Disponível em:

https://www2.camara.leg.br/legin/fed/emecon/1998/emendaconstitucional-19-4-junho-1998372816-exposicaodemotivos-148914-pl.html. Acesso em: 23 mai. 2019.

BRASIL. Casa Civil - CC. Notícias. Programa Brasil Eficiente vai modernizar gestão e simplificar acesso a serviços. Brasília, 2017. Disponível em:

http://www.casacivil.gov.br/central-de-conteudos/noticias/2017/junho/governo-priorizamedidas-para-modernizar-gestao-e-simplificar-acesso-a-servicos. Acesso em: 18 mai. 2019.

BRASIL. Casa Civil. Emenda Constitucional n 19, de 04 de junho de 1998. Modifica o regime e dispõe sobre princípios e normas da Administração Pública, servidores e agentes 
políticos, controle de despesas e finanças públicas e custeio de atividades a cargo do Distrito Federal, e dá outras providências. Disponível em:

http://www.planalto.gov.br/ccivil_03/constituicao/emendas/emc/emc19.htm. Acesso em: 23 mai. 2019.

BRASIL. Decreto de 07 de março de 2017. Cria o Conselho Nacional para a Desburocratização - Brasil Eficiente e dá outras providências. Disponível em: http://www.planalto.gov.br/ccivil_03/_ato2015-2018/2017/dsn/Dsn14451.htm. Acesso em: 18 mai. 2019.

BRASIL. Decreto Lei no 200, de 25 de fevereiro de 1967. Dispõe sobre a organização da Administração Federal, estabelece diretrizes para a Reforma Administrativa e dá outras providências. Disponível em: http://www.planalto.gov.br/ccivil_03/_ato20152018/2018/lei/L13726.htm. Acesso em: 12 mai. 2019.

BRASIL. Decreto $\mathbf{n}^{\circ}$ 8.936, de 19 de dezembro de 2016. Institui a Plataforma de Cidadania Digital e dispõe sobre a oferta dos serviços públicos digitais, no âmbito dos órgãos e das entidades da administração pública federal direta, autarquia e fundacional. Disponível em: http://www.planalto.gov.br/ccivil_03/_Ato2015-2018/2016/Decreto/D8936.htm. Acesso em 19 mai. 2019.

BRASIL. Decreto no 9.094, de 17 de julho de 2017. Regulamenta dispositivos da Lei $\mathrm{n}^{\circ}$ 13.460, de 26 de junho de 2017. Disponível em:

http://www.planalto.gov.br/ccivil_03/_ato2015-2018/2017/decreto/d9094.htm. Acesso em 19 mai. 2019.

BRASIL. Decreto $\mathrm{n}^{\circ}$ 9.203, de 22 de novembro de 2017. Dispõe sobre a política de governança da administração pública federal direta, autárquica e fundacional. Disponível em: https://www2.camara.leg.br/legin/fed/decret/2017/decreto-9203-22-novembro-2017-785782publicacaooriginal-154277-pe.html. Acesso em: 19 mai. 2019.

BRASIL. Decreto $\mathbf{n}^{\circ}$ 9.670, de 02 de janeiro de 2019. Aprova a Estrutura Regimental e o Quadro Demonstrativo dos Cargos em Comissão e das Funções de Confiança da SecretariaGeral da Presidência da República. Disponível em:

http://www.planalto.gov.br/CCIVIL_03/_Ato2019-2022/2019/Decreto/D9670.htm. Acesso em: 19 mai. 2019.

BRASIL. Decreto $\mathbf{n}^{\mathbf{0}}$ 9.745, de 08 de abril de 2019. Aprova a Estrutura Regimental e o Quadro Demonstrativo dos Cargos em Comissão e das Funções de Confiança do Ministério da Economia. Disponível em: http://www.planalto.gov.br/ccivil_03/_ato20192022/2019/Decreto/D9745.htm. Acesso em: 19 mai. 2019.

BRASIL. Decreto no 9.756, de 11 de abril de 2019. Institui o portal único "gov.br" e dispõe sobre as regras de unificação dos canais digitais do Governo federal. Disponível em: http://www.planalto.gov.br/ccivil_03/_ato2019-2022/2019/decreto/D9756.htm. Acesso em 19 mai. 2019. 
BRASIL. Lei $\mathbf{n}^{\mathbf{0}}$ 13.726, de 08 de outubro de 2018. Racionaliza atos e procedimentos administrativos dos Poderes da União, dos Estados, do Distrito Federal e dos Municípios e institui o Selo de Desburocratização e Simplificação. Disponível em:

http://www.planalto.gov.br/ccivil_03/decreto-lei/Del0200compilado.htm. Acesso em 12 mai. 2019.

BRASIL. Ministério da Economia. Brasileiros terão portal único "gov.br" para acessar informações e serviços públicos. Brasília, 12 de abr. 2019. Disponível em:

http://www.economia.gov.br/noticias/2019/04/brasileiros-terao-portal-unico-201cgov-br201dpara-acessar-informacoes-e-servicos-publicos. Acesso em: 02 jun. 2019.

BRASIL. Planejamento, Desenvolvimento e Gestão. Economia com implantação de serviços digitais pode gerar economia de $97 \%$ aos cofres públicos. Brasília, 10 de jul. 2017. Disponível em: http://www.brasil.gov.br/governo/2017/07/servicos-digitais-podemgerar-economia-de-97-aos-cofres-publicos. Acesso em: 04 jun. 2019.

BRASIL. Tribunal de Contas da União. Acórdão no 1103/2019. Plenário. Relator: Ministro Vital do Rêgo. Sessão de 15/052019, Plenário. Disponível em:

https://pesquisa.apps.tcu.gov.br/\#/documento/acordaocompleto/2328320181.PROC/\%20/DTRELEVANCIA\%20desc,\%20NUMACORDAOINT\% 20desc/0/\%20?uuid=a05d0590-8984-11e9-bfaa-672d8cfa2a85. Acesso em: 07 jun. 2019.

BRASIL. Tribunal de Contas da União. Acórdão no 2.151/2015. Plenário. Relator: Ministro Bruno Dantas. Sessão de 26/08/2015. Disponível em:

https://pesquisa.apps.tcu.gov.br/\#/documento/acordao-

completo/*/NUMACORDAO\%253A2151\%2520ANOACORDAO\%253A2015/DTRELEVA NCIA\%20desc, $\% 20$ NUMACORDAOINT\%20desc/0/\%20?uuid=24dba450-ccb2-11e9-949b5d867145611c. Acesso em 04 jun. 2019.

CARVALHO, Victor Nunes. O princípio da eficiência e a reforma administrativa do Estado brasileiro a partir da EC no 19/98. Revista Jus Navigandi, ISSN 1518-4862, Teresina, ano 21, n. 4784, 6 ago. 2016. Disponível em: https://jus.com.br/artigos/35060. Acesso em: 23 mai. 2019.

CEARÁ. Secretaria do Planejamento e Gestão do Governo do Estado do Ceará - SEPLAG. Ceará quer implantar governo 100\% digital em quatro anos. Ceará, 20 fev. 2019. Disponível em: https://www.ceara.gov.br/2019/02/20/ceara-quer-implantar-governo-100digital-em-quatro-anos/. Acesso em: 02 jun. 2019.

CHICÓSKI, Davi. Burocracia e legitimação: fundamentos do procedimento administrativo eficiente. A \& C: Revista de Direito Administrativo e Constitucional, Belo Horizonte, v. 4, n. 15, jan. 2004. Disponível em: http://bdjur.stj.jus.br/dspace/handle/2011/30475. ISSN: 1516-3210. e-ISSN 1984-4182. Acesso em: 24 mai. 2019.

CHICÓSKI, Davi. O princípio da eficiência e o procedimento administrativo. Revista de Direito Administrativo, Rio de Janeiro, v. 237, p. 93-118, jul. 2004. ISSN 2238-5177. 
Disponível em: http://bibliotecadigital.fgv.br/ojs/index.php/rda/article/view/44368. Acesso em: 24 mai. 2019. doi: http://dx.doi.org/10.12660/rda.v237.2004.44368.

CORDEIRO, Wagner Marques. Burocracia na construção da administração pública do século XXI: uma reflexão teórica. João Pessoa. 2017. Encontro Brasileiro de Administração Pública. Disponível em http://www.ufpb.br/ebap/contents/documentos/0851-867-burocraciana-construcao-da.pdf. Acesso em: 22 maio 2019.

FIESP - Federação das Indústria do Estado de São Paulo. Sociedade e indústria veem burocracia brasileira como obstáculo ao desenvolvimento. São Paulo, 17 out. 2017. Disponível em: https://www.fiesp.com.br/noticias/sociedade-e-industria-veem-burocraciabrasileira-como-obstaculo-ao-desenvolvimento/. Acesso em: 22 maio 2019.

FORTALEZA. Prefeitura de Fortaleza. Notícias. Prefeitura publica decreto de desburocratização dos serviços públicos. Fortaleza, 2019. Disponível em: https://www.fortaleza.ce.gov.br/noticias/prefeitura-publica-decreto-de-desburocratizacao-dosservicos-publicos. Acesso em: 12 mai. 2019.

FORTALEZA. Prefeitura de Fortaleza. Notícias. Prefeito Roberto Cláudio apresenta Programa Fortaleza Competitiva. Fortaleza, 2017. Disponível em: https://www.fortaleza.ce.gov.br/noticias/prefeito-roberto-claudio-apresenta-programafortaleza-competitiva. Acesso em: 12 mai. 2019.

GOMES, Betinho. Projeto de Lei $\mathbf{n}^{\mathbf{0}} \mathbf{7 . 0 6 4}$, de 17 de outubro de 2017. Racionaliza e simplifica atos e procedimentos administrativos dos Poderes da União, dos Estados, do Distrito Federal e dos Municípios. Disponível em:

https://www.camara.leg.br/proposicoesWeb/prop_mostrarintegra;jsessionid=CDD3D9237DE 49FA12FE3A92098CB8D44.proposicoesWebExterno1 ?codteor $=1610481 \&$ filename=Tramit acao-PL+7064/2017. Acesso em 19 mai. 2019.

HSM. Sociedade Digital: a transformação que ajudou a Estônia a desburocratizar os serviços públicos. São Paulo, 2018. Online, 03 set. 2018. Disponível em:

https://www.hsm.com.br/sociedade-digital-a-transformacao-que-ajudou-a-estonia-adesburocratizar-os-servicos-publicos/. Acesso em 07 jun 2019.

LOUREIRO, João Carlos Simões Gonçalves. O Procedimento Administrativo entre a Eficiência e a Garantia dos Particulares: algumas considerações. In: Boletim da Faculdade de Direito de Coimbra. Coimbra: Coimbra Editora, 1995.

MERTON, Robert K. Sociologia: Teoria e Estrutura. Tradução de Miguel Maillet. São Paulo: Mestre Jou, 1970.

NOHARA, Irene Patrícia. Reforma administrativa e burocracia: impacto da eficiência na configuração do direito administrativo brasileiro. São Paulo: Atlas, 2012, p. 29.

OLIVEIRA, Aroldo Cedras (Coord.). O controle da administração pública na era digital.

2. ed. Belo Horizonte: Forum, 2017. 
ONU - Organização das Nações Unidas. Departamento de Assuntos Econômicos e Sociais Estudo sobre governo eletrônico da Organização das Nações Unidas 2018. Nova York, 2018. Disponível em: https://publicadministration.un.org/egovkb/en-us/Reports/UN-EGovernment-Survey-2018. Acesso em: 18 mai. 2019.

PADILHA, Eliseu. Casa Civil. Brasil Eficiente: Governo Federal conclui 78 medidas de desburocratização. Notícia publicada em 06/03/2018 no portal da Casa Civil. Disponível em: http://www.casacivil.gov.br/central-de-conteudos/noticias/2018/marco/brasil-eficientegoverno-federal-conclui-78-medidas-de-desburocratizacao. Acesso em: 19 mai. 2019.

PEREIRA, Luiz Carlos Bresser. Exposição no Senado sobre a Reforma da Administração Pública. Brasília. Ministério da Administração Federal e Reforma do Estado, 1997.

PEREZ, Caio Frederico Fonseca Martinez. Burocracia estável e o princípio da eficiência na administração pública brasileira. 2016. Tese (Doutorado em Direito do Estado) - Faculdade de Direito, Universidade de São Paulo, São Paulo, 2016. doi:10.11606/T.2.2016.tde03112016-223544. Acesso em: 14 maio 2019.

QUEIROZ, Isis (2014). Burocracia X Eficiência: O princípio do formalismo moderado como ferramenta de eficiência na Gestão Pública. Disponível em:

http://isisqueiroz.jusbrasil.com.br/artigos/112105696/burocracia-X-eficiencia-o-principio-doformalismo-moderado-como-ferramenta-de-eficiencia-na-gestao-publica. Acesso em: 23 mai. 2019.

RUBIN, Gleisson. Dados sobre desempenho de serviços públicos estão disponíveis no Portal de Serviços do Governo Federal. Brasília, 19 jan. 2018. Disponível em: http://www.planejamento.gov.br/noticias/dados-sobre-desempenho-de-servicos-publicosestao-disponiveis-no-portal-de-servicos-do-governo-federal-1. Acesso em 19 maio 2019.

SILVA, Camila Cardoso Fontes. A desaplicaçãodo princípio constitucional da eficiência da administração pública. 2017. Disponível em:

https://www.direitonet.com.br/artigos/exibir/9804/A-des-aplicacao-do-principio-

constitucional-da-eficiencia-na-Administracao-Publica. Acesso em: 14 dez. 2019.

VIOLIN, Tarso Cabral. Da Administração Pública patrimonialista à Administração Pública gerencial e a burocracia. A\&C R. de Dir. Administrativo \& Constitucional, Belo Horizonte, ano 7, n. 30, p. 225-247, out/dez. 2007. Disponível em:

http://www.revistaaec.com/index.php/revistaaec/article/view/646. Acesso em: 22 maio 2019.

WEBER, Max. Burocracia, in. Ensaios de Sociologia. 5a ed. Rio de Janeiro: LTC, 1946. 